\title{
Incompetencia manifiesta y usurpación de funciones
}

\author{
Alberto Picón Arranz (España) \\ Universidad de Valladolid \\ albicon11@gmail.com
}

\section{NOTA BIOGRÁFICA}

Alberto Picón Arranz, Licenciado en Derecho por la Universidad de Valladolid (2010). Actualmente Personal Investigador Predoctoral y Profesor Asociado del Área de Derecho Administrativo en la Universidad de Valladolid.

\section{RESUMEN}

La interpretación restrictiva inherente a las causas de nulidad de pleno derecho reduce los supuestos encuadrables en el vicio de incompetencia a los actos dictados por órgano manifiestamente incompetente en el ámbito interno de las Administraciones Públicas. Los supuestos de usurpación de funciones no encajarían en esta causa de nulidad. Únicamente serán actos nulos de pleno derecho si son constitutivos de delito, de lo contrario estaremos ante actos meramente anulables.

\section{PALABRAS CLAVE}

Incompetencia; invalidez; nulidad de pleno derecho; infracción penal.

\section{ABSTRACT}

The specific restrictive interpretation of nullity cases reduces the cases of manifest incompetence to acts dictated by an incompetent body within the Public Administrations. The assumptions of usurpation of functions would not fit into this cause of nullity. They will only be null if they constitute a criminal offence, otherwise we will be faced with acts that can only be annulled.

\section{KEYWORDS}

Incompetence; invalidity; nullity; criminal offence.

\section{SUMARIO}

I. INTRODUCCIÓN. II. EL CONCEPTO DE COMPETENCIA: EL ELEMENTO SUBJETIVO DEL ACTO ADMINISTRATIVO POR ANTONOMASIA. III. EL VICIO DE INCOMPETENCIA: FUNDAMENTO DE SU VINCULACIÓN HISTÓRICA CON LA NULIDAD DE PLENO DERECHO. IV. INVASIÓN COMPETENCIAL DE LAADMINISTRACIÓN EN LA ESFERA PROPIA DE OTRO PODER DEL ESTADO. V. USURPACIÓN DE COMPETENCIAS ADMINISTRATIVAS POR UNA PERSONA PRIVADA. VI. CONCLUSIONES. VII. REFERENCIAS BIBLIOGRÁFICAS. 


\section{INTRODUCCIÓN}

La presente comunicación trae causa en la celebración del VI Seminario "La reforma del Estado: El régimen de la invalidez en el ámbito del derecho administrativo", que tuvo lugar en el Instituto Nacional de Administración Pública el día 10 de octubre de 2018.

Nuestro sistema jurídico-administrativo reconoce dos grados de invalidez en función de la gravedad del vicio y de su afección al orden público. En primer lugar, los supuestos de ilegalidad más flagrantes y manifiestos se calificarán como nulos de pleno derecho y se encuentran tasados en el artículo 47.1 de la Ley 39/2015, de Procedimiento Administrativo Común de las Administraciones Públicas. En segundo lugar, el resto de infracciones del ordenamiento jurídico con efectos invalidantes, serán meramente anulables.

El análisis de las diferencias de régimen jurídico entre la nulidad de pleno derecho y la anulabilidad bien darían para otro artículo, baste decir por el momento, como quedó sobradamente demostrado en el Seminario, que la ausencia de plazos, en principio, para declarar un acto como nulo de pleno derecho genera una gran inseguridad jurídica. Para evitarlo, es importante identificar qué supuestos son encuadrables entre los tasados en el artículo 47.1. Esta identificación se deberá hacer teniendo en cuenta que la categoría de la nulidad de pleno derecho merece siempre una interpretación restrictiva y tiene carácter excepcional.

En esta comunicación trataremos de concretar algunos de los supuestos encuadrables en el artículo 47.1.b), relativo al vicio de incompetencia manifiesta. El vicio de incompetencia es el que goza de mayor tradición dentro de los vicios de nulidad de pleno derecho ${ }^{1} \mathrm{y}$, en numerosas ocasiones, se utiliza la incompetencia como "cajón de sastre» al que se reconducen supuestos que, o bien son meramente anulables o bien su nulidad de pleno derecho queda encuadrada en otra de las causas enumeradas en el citado artículo 47.

\section{EL CONCEPTO DE COMPETENCIA: EL ELEMENTO SUBJETIVO DEL ACTO ADMINISTRATIVO POR ANTONOMASIA}

Recurrimos a la histórica definición de D'ALESSIO quien define la competencia como «la medida de la potestad conferida a cada órgano» ${ }^{2}$. La importancia de la competencia radica en que esa atribución de potestad a cada órgano se realiza mediante el derecho objetivo que, en último término, responde al interés público. Este concepto ha sido asumido por la doctrina española, como ejemplo traemos a colación la definición de competencia del profesor GARCÍA-TREVIJANO, que entiende la competencia como el «conjunto de facultades, de poderes, de atribuciones que corresponden a un determinado órgano en relación con los demás» ${ }^{3}$. En definitiva, la competencia es una habilitación al órgano para que pueda actuar válidamente en la esfera jurídica. Completaríamos esta definición añadiendo que los poderes de un órgano de la Administración le son atribuidos siempre por una norma en función de los fines que el órgano tenga asignados ${ }^{4}$.

En consecuencia, la competencia es el presupuesto habilitante, previo y necesario para que un órgano de la Administración Pública pueda actuar válidamente ${ }^{5}$. Y también este carácter previo y habilitante es el que confiere a la competencia la naturaleza de elemento esencial del acto administrativo, sin el cual, puede llegar a calificarse como nulo de pleno derecho.

Es más, pese a que la competencia en sentido estricto es la que debe ostentar el órgano administrativo actuante, la idea de la competencia sirve de sustrato, de mayor o menor manera, a todos los elementos subjetivos del acto administrativo, lo cual no quiere decir que la ausencia o defecto en cualquier elemento subjetivo del acto pueda dar lugar a un vicio de nulidad de pleno derecho.

\footnotetext{
1 Cfr. SANTAMARÍA PASTOR, J. A. (1972): La nulidad de Pleno Derecho de los Actos Administrativos. Contribución a una teoría de la ineficacia en el derecho público, Madrid: Instituto de Estudios Administrativos, pág. 317 y FERNÁNDEZ RODRÍGUEZ, T. R. (1970): La doctrina de los vicios de orden público, Madrid: Instituto de Estudios de Administración Local, pág. 260.

2 D’ALESSIO, F. (1932): Istituzioni di Diritto Amministrativo Italiano, Volume Primo, Torino: Editrice Torinese, pág. 230, «la misure della potestá spettante a ciascun ufficio».

${ }^{3}$ GARCÍA-TREVIJANO FOS, J. A. (1957): Principios Jurídicos de la organización administrativa, Madrid: Instituto de Estudios Políticos, pág. 186.

${ }^{4}$ En este sentido, cfr. BOQUERA OLIVER, J. M. (1986): Derecho Administrativo I, Madrid: Civitas, pág. 246 y GONZÁLEZ NAVARRO, F. (1994): Derecho Administrativo Español. Tomo II, Pamplona: Eunsa, pág. 319.

${ }_{5}^{5}$ Cfr. BELAdíEZ ROJO, M. \& NIETO, A. (1994): Validez y eficacia de los actos administrativos, Madrid: Marcial Pons, pág. 116.
} 
Nos estamos refiriendo en este momento a las atribuciones en sentido amplio como presupuesto habilitador necesario para dar validez a la actuación de un poder público, más allá de la competencia en sentido estricto que es propia de cada órgano administrativo y a la que alude el artículo 47.1.b).

\section{EL VICIO DE INCOMPETENCIA: FUNDAMENTO DE SU VINCULACIÓN HISTÓRICA CON LA NULIDAD DE PLENO DERECHO}

El vicio de incompetencia surge en el seno del derecho administrativo francés, en concreto, en el recurso por exceso de poder. Más correctamente podríamos decir que es el propio vicio de incompetencia el que da origen al recurso por exceso de poder. La propia literalidad de la expresión «exceso de poder» es significativa, pues denota que la Administración se ha extralimitado en sus funciones, es decir, ha salido de su competencia.

Significativo en este sentido es el pensamiento de HAURIOU acerca del vicio de incompetencia, que califica como el primero y el más grave de todos los vicios en que puede incurrir el acto administrativo. Mientras que el resto de vicios, -lo que el profesor denomina vicios de invalidez o ilegalidad- están dentro de los límites de la actuación de la Administración, el vicio de incompetencia se encuentra fuera de sus límites de acción ${ }^{6}$. Por ello, entre todos los vicios del acto, la incompetencia es el más pernicioso para el sistema, pues supone una violación de las normas más elementales que reparten -y en consecuencia limitan- el poder de los entes públicos.

En definitiva, la competencia es el primer y fundamental presupuesto de una correcta actividad administrativa $^{7}$. Consecuencia de lo anterior es su carácter irrenunciable ${ }^{8}$. Entender la competencia como el reparto de atribuciones entre los poderes públicos eleva su posición a una cuestión de orden público ${ }^{9}$. La transcendencia de su vulneración podrá llevar, en los casos de máxima gravedad, a la nulidad de pleno derecho de la actuación que se trate.

El derecho administrativo español determina que sólo serán nulos de pleno derecho los actos administrativos dictados por órgano «manifiestamente incompetente por razón de la materia o del territorio» ${ }^{10}$. El legislador entiende la competencia como un concepto predicable exclusivamente del órgano administrativo, sin embargo, no es difícil encontrar en la doctrina o en la jurisprudencia interpretaciones extensivas de este supuesto de nulidad. Así, se llegan a incluir las invasiones competenciales de la Administración en la esfera propia de otros poderes del Estado o la usurpación de competencias administrativas por una persona privada.

Pese a que la idea de incompetencia sobrevuela a las hipótesis planteadas, éstas no encajan en el artículo 47.1.b), pues éste no ofrece dudas en que se está refiriendo exclusivamente a los supuestos de incompetencia orgánica.

Si algo caracteriza a la categoría de la nulidad de pleno derecho es su interpretación restrictiva, pues supone un estado de inseguridad jurídica nada recomendable en Derecho. Sin embargo, en lo que al vicio de incompetencia se refiere, parece que no se está cumpliendo esta regla. No queremos decir con esto que no podamos estar ante supuestos de nulidad de pleno derecho cuando la Administración invade competencias del Poder Judicial o del Legislativo, o cuando un particular usurpa funciones públicas, pues su gravedad salta a la vista, pero quizás puedan incluirse en otro de los supuestos tasados en el artículo 47.

Examinaremos a continuación ambas hipótesis determinando, en primer lugar, si estamos ante supuestos de nulidad de pleno derecho y, en caso afirmativo, donde pueden encajar dentro del esquema que nos ofrece el legislador en el artículo 47.1.

\footnotetext{
${ }^{6}$ Cfr. HAURIOU M. (1943): Précis Elementarie Droit Administratif, ed. 5. ${ }^{a}$, Paris, pág. 255.

7 Cfr. FERNÁNDEZ RODRÍGUEZ, T. R. (1970): La doctrina de los vicios de orden público, Madrid: Instituto de Estudios de Administración Local, pág. 270.

8 Vid. GONZÁLEZ NAVARRO, F. (1994): Derecho Administrativo Español. Tomo II, Pamplona: Eunsa, pág. 320.

9 En este sentido, GARCÍA DE ENTERRÍA, E. \& FERNÁNDEZ RODRÍGUEZ, T. R. (2015): Curso de Derecho administrativo I, Ed. 17. ${ }^{a}$, Cizur Menor: Civitas, pág. 680.

10 Respecto de la incompetencia por razón de jerarquía o de grado, doctrina y jurisprudencia parecen estar de acuerdo en que cuando la distancia jerárquica sea insalvable o cuando la norma que atribuye la competencia al órgano lo haga de manera expresa, exclusiva e indelegable, estamos ante actos nulos de pleno derecho encuadrables dentro de la incompetencia por razón de la materia. En este sentido, cfr. TRAYTER JIMÉNEZ, J. M., (1994): "Las causas de nulidad de pleno derecho de los actos administrativos" en Administración Pública y Procedimiento Administrativo. Comentarios a la Ley 30/1992, Barcelona: Bosch, pág. 263, BELADÍEZ ROJO, M. (1994): “La nulidad y la anulabilidad. Su alcance y significación”, en RAP, núm. 133, pág. 173.
} 


\section{INVASIÓN COMPETENCIAL DE LA ADMINISTRACIÓN EN LA ESFERA PROPIA DE OTRO PODER DEL ESTADO}

Aunque el legislador en el artículo 47.1.b) sólo se refiere a los supuestos de incompetencia del órgano administrativo, parece obvio que en un Estado de Derecho no hay mayor vicio de incompetencia que aquél en que la propia Administración invade competencias del poder legislativo o del poder judicial ${ }^{11}$.

Desde este punto de vista, la competencia encarna la función del reparto de poder entre los poderes del Estado. Es garantía, por tanto, de la división de poderes. Pocas situaciones pueden imaginarse más contrarias al orden público que poner en jaque la división de poderes, principio básico del Estado de Derecho.

En consecuencia, cualquier acto de la Administración Pública que invada las competencias o funciones propias de otro poder del Estado debe ser calificado como nulo de pleno derecho ${ }^{12}$. Sin embargo, el legislador no está pensando en estos supuestos cuando configura el contenido del vicio de incompetencia manifiesta, pues está pensando exclusivamente en la distribución competencial que tiene lugar en el seno interno de las Administraciones Públicas.

Justificada la gravedad de estos supuestos y su afección al orden público, el siguiente paso es encontrar una causa de nulidad de pleno derecho donde encajen estas conductas. A estos efectos nos es útil acudir al Código Penal, que tipifica la usurpación de funciones en el artículo 506 como «la autoridad o funcionario público que, careciendo de atribuciones para ello, dictare una disposición general o suspendiere su ejecución» y en el artículo 508 como «la autoridad o funcionario público que se arrogare atribuciones judiciales o impidiere ejecutar una resolución dictada por la autoridad judicial competente». En definitiva, se califica como delictiva la conducta del funcionario público que, sin competencia para ello, ejerza competencias judiciales o legislativas.

Si las hipótesis de invasión competencial de la Administración en la esfera propia del poder legislativo o del poder judicial son tipificadas como delito en nuestro Código Penal, esto nos ofrece una solución para que los actos administrativos dictados como consecuencia de esa invasión competencial sean nulos de pleno derecho. En efecto, dentro de las causas tasadas de nulidad del artículo 47.1, en su apartado d) se incluyen los actos «que sean constitutivos de infracción penal o se dicten como consecuencia de ésta».

Por lo tanto, si para incluir estos supuestos dentro de la incompetencia manifiesta deberíamos realizar una interpretación flexible del artículo 47.1.b), lo cual es contrario al carácter restrictivo de las causas de nulidad, acudiendo a la nulidad de los actos constitutivos de infracción penal o consecuencia de ésta encajamos de manera menos forzada estos actos dentro de los calificables como nulos de pleno derecho.

\section{USURPACIÓN DE COMPETENCIAS ADMINISTRATIVAS POR UNA PERSONA PRIVADA}

Parece complicado, en abstracto, imaginar una usurpación de funciones administrativas por una persona privada que termine con la emisión de un acto administrativo por el particular. En principio, el acto administrativo requiere ser dictado por la Administración Pública. En el supuesto que tratamos, si un particular dictase un acto administrativo, no tendría tal condición y, en consecuencia, no cabe plantearse si es válido o inválido, pues sería inexistente ${ }^{13}$.

Pero, si en una circunstancia excepcional, una persona privada sin habilitación de ningún tipo dictase un acto administrativo con una mínima apariencia de tal ${ }^{14}$, la gravedad de la conducta está fuera de toda duda y la doctrina coincide en que estaríamos también ante un acto nulo de pleno derecho. La argumentación radica

11 En este sentido, cfr. GARCÍA LUENGO, J. (2002): La nulidad de pleno derecho de los actos administrativos, Madrid: Civitas, pág. 187, exponiendo como ejemplo de incompetencia de este tipo que el Ministerio de Administraciones Públicas imponga una sanción disciplinaria a un empleado de las Cortes Generales. Igualmente, el mismo autor, cfr. GARCÍA LUENGO, J., (2016): Las infracciones formales como causa de invalidez del acto administrativo. Un estudio sobre el artículo 48.2 de la ley 39/2015, Ed. 1. , Madrid: Iustel, pág. 36, poniendo como ejemplo el acto de una Comunidad Autónoma que pretende imponer una sanción disciplinaria a un juez.

12 Cfr. GARCÍA DE ENTERRÍA, E., \& FERNÁNDEZ RODRÍGUEZ, T. R. (2015): Curso de Derecho administrativo I, ed. 17. a , Cizur Menor: Civitas, pág. 681, donde se afirma que «la falta de potestad es el supuesto máximo de incompetencia, el más grave y manifiesto de todos», TRAYTER JIMÉNEZ, J. M., (1994): "Las causas de nulidad de pleno derecho de los actos administrativos" en Administración Pública y Procedimiento Administrativo. Comentarios a la Ley 30/1992, Barcelona: Bosch, pág. 266. pág. 216.

13 Cfr. GARRIDO FALLA, F. (1956): Régimen de impugnación de los actos administrativos, Madrid: Instituto de Estudios Políticos,

14 Íbidem, pág. 220. Es absolutamente necesaria esa apariencia de validez que pueda inducir a error a terceros, pues sino estaríamos ante una «falta absoluta de acto administrativo». 
en que las normas atributivas de competencia exigen el ejercicio de potestades públicas a los poderes públicos. No puede un particular, sin más, ejercitar potestades públicas pues invadiría una esfera jurídica que no le corresponde pues no tiene la condición de poder público. Esta circunstancia es, en todo caso, grave y atenta contra el orden público. Sin embargo, al igual que ocurría en el supuesto analizado más arriba, la nulidad por incompetencia manifiesta no incluye este tipo de conductas, pues se limita al ámbito interno de las Administraciones Públicas.

Exactamente igual que en el supuesto anterior, acudir al Código Penal nos da una solución satisfactoria para incluir este tipo de actos entre los calificables como nulos de pleno derecho. Concretamente, el artículo 402 del Código Penal tipifica como delito la usurpación de funciones públicas por los particulares, concretamente «el que ilegítimamente ejerciere actos propios de una autoridad o funcionario público atribuyéndose carácter oficial».

Mediante un razonamiento análogo al llevado a cabo anteriormente, los supuestos de usurpación de competencias administrativas por particulares, pueden reconducirse a la categoría de la nulidad de pleno derecho vía artículo 47.1.d). La tipificación de estas conductas como delictivas ofrece una solución más natural para calificar este tipo de actos como nulos de pleno derecho sin necesidad de interpretar extensivamente el supuesto de la incompetencia manifiesta.

Fuera de los supuestos encuadrables dentro del delito de usurpación de funciones públicas, entendemos que los defectos que puedan concurrir en el titular del órgano administrativo no podrán, en principio, determinar la nulidad de pleno derecho de sus actos.

Especialmente llamativos son los supuestos relativos a la invalidez de los actos emanados de funcionarios cuyo nombramiento ha expirado por el transcurso del plazo normativamente previsto para el desempeño de sus atribuciones.

La Sentencia del Tribunal Supremo 1067/2017, de 16 de junio (FD 3) calificó de nula de pleno derecho una liquidación tributaria llevada a cabo por el Jefe de la Inspección Territorial de Barcelona el 27 de noviembre de 2009, cuando sus funciones -encomendadas por la Agencia Tributaria de Catalunya mediante la figura del encargo de servicios-, habían cesado pues había expirado el plazo el 2 de julio de 2008.

La solución que ofrece la citada Sentencia no ofrece dudas, pues equipara estos supuestos a los de usurpación de funciones púbicas por persona privada, entendiendo que constituyen el «supuesto más grave de nulidad de pleno derecho, pues la actuación del funcionario sin nombramiento carecía de validez alguna, por manifiesta y grave incompetencia material del funcionario, en tanto que lleva a cabo unas atribuciones y competencias que le resultaban ajenas y extrañas». En un supuesto análogo, la STS 1093/2017, de 20 de junio (FD 5) llega incluso a la conclusión de que se trata de un "grosero vicio de legalidad que arrastra consigo la inexistencia jurídica de los actos dictados, pues se trata de una actividad desplegada al margen de la Administración».

Como venimos argumentando, la causa de nulidad de incompetencia manifiesta no incluye este tipo de supuestos de hecho relativos a particulares que ejercen funciones públicas, pues sólo hace referencia a actos dictados por órganos administrativos manifiestamente incompetentes, y en estos supuestos el órgano es competente al margen de que pueda haber irregularidades en su titular.

En conclusión, salvo que estemos ante un supuesto de delito de usurpación de funciones públicas reconducible a la nulidad vía artículo 47.1.d) -que podría plantearse en este caso concreto dado que ha pasado casi un año y medio desde el cese del funcionario en su cargo-, los actos se podrán calificar, a lo sumo, como anulables. Para ello, tendremos que estar a las circunstancias del caso concreto, pues no es lo mismo que el funcionario haya dejado de ser competente por un día o por un año ${ }^{15}$. Tampoco es lo mismo que estemos ante un acto reglado o discrecional. Y, por último, tampoco podemos dar el mismo trato a un acto cuyo contenido se ajusta a la legalidad plenamente o, por el contrario, está repleto de vulneraciones normativas de fondo ${ }^{16}$.

La cuestión no ofrece tanta claridad como pretende demostrar el Tribunal Supremo. No podemos concluir que el funcionario ejerce funciones completamente «ajenas y extrañas».

15 No compartimos el fallo de la STS 8055/2005, de 3 de noviembre, (FD 3), que declara la nulidad por incompetencia manifiesta de un acto dictado el 5 de julio por una autoridad que había cesado en su cargo el 2 de julio del mismo año sin aludir en ningún momento a la mala fe, sino simplemente a que no se trata de un error material.

16 GARCÍA-TREVIJANO FOS, J. A. (1986): Los actos administrativos, Fuenlabrada: Civitas, pág. 392, entiende que sólo cabrá la nulidad de pleno derecho si el tiempo esté previsto como "esencialísimo», sino estaríamos ante simple anulabilidad e incluso ante un vicio no invalidante si su trascendencia es mínima. 
Rechazamos, en definitiva, que estemos ante una situación equiparable a la usurpación de funciones públicas, y consideramos que los principios de seguridad jurídica, confianza legítima y economía procesal deben jugar un papel importante a la hora de plantearse la invalidez de este tipo de actos. Descartada la nulidad de pleno derecho, la calificación de estos actos como anulables deberá valorarse en cada caso concreto. Parece que un acto dictado por un funcionario de buena fe, cuyo nombramiento ha expirado el día anterior y que consiste en el otorgamiento de una licencia tras la comprobación de una serie de requisitos tasados y reglados por la ley que efectivamente cumple el solicitante no debe ser nulo de pleno derecho en ningún caso.

\section{CONCLUSIONES}

1. El vicio de incompetencia manifiesta es uno de los vicios de nulidad de pleno derecho del acto administrativo con mayor recorrido histórico e importancia. Actualmente, el legislador reconoce como nulos de pleno derecho los actos «dictados por órgano manifiestamente incompetente por razón de la materia o del territorio».

2. Tal y como configura el legislador este supuesto de nulidad de pleno derecho, los supuestos encuadrables en él se reducen a supuestos de incompetencia manifiesta, grave y en el ámbito interno de la Administración Pública. Pese a esto, doctrina y jurisprudencia incluyen extensivamente entre los supuestos de nulidad de pleno derecho por incompetencia manifiesta actos de la Administración que supongan invasión competencial en la esfera de otros poderes del estado (legislativo o judicial) y actos administrativos dictados por particulares mediante usurpación de funciones públicas.

3. El carácter restrictivo inherente a la categoría de la nulidad de pleno derecho nos hace replantearnos los supuestos encuadrables en el vicio de incompetencia manifiesta. Pese a que la invasión competencial de otros poderes del Estado por la Administración y la usurpación de funciones públicas por el particular son supuestos muy graves y dignos de ser calificados como nulos de pleno derecho, consideramos que la vía técnicamente más correcta no es la de la incompetencia manifiesta, sino la de los actos «que sean constitutivos de infracción penal o se dicten como consecuencia de ésta» del artículo 47.1.d), ya que nuestro Código Penal tipifica estas conductas como delictivas.

4. La usurpación de funciones públicas no es una situación aplicable a la del funcionario cuyo nombramiento ha expirado por el transcurso del plazo normativamente previsto para el desempeño de sus atribuciones. Pese a que encontramos Sentencias del Tribunal Supremo que califican estos actos como nulos de pleno derecho por incompetencia manifiesta por razón de la materia, entendemos que no pueden ser constitutivos de nulidad de pleno derecho, pues ni se encuadran en supuestos de incompetencia orgánica de la Administración, ni en supuestos calificables como delito de usurpación de funciones públicas. A lo sumo, podrán ser actos anulables valorando las circunstancias del caso concreto: confianza generada en los terceros destinatarios, plazo transcurrido desde la expiración del nombramiento, que estemos ante un acto reglado o discrecional o que el contenido del acto sea o no acorde a la legalidad.

\section{REFERENCIAS BIBLIOGRÁFICAS}

BELAdÍEZ ROJO, M. \& NIETO, A. (1994): Validez y eficacia de los actos administrativos, Madrid: Marcial Pons. BELADÍEZ ROJO, M. "La nulidad y la anulabilidad. Su alcance y significación”, en RAP, núm. 133, págs. 155-187. BOQUERA OLIVER, J. M. (1986): Derecho Administrativo I, Madrid: Civitas.

D'ALESSIO, F. (1932): Istituzioni di Diritto Amministrativo Italiano, Volume Primo, Torino: Editrice Torinese.

FERNÁNDEZ RODRÍGUEZ, T. R. (1970): La doctrina de los vicios de orden público, Madrid: Instituto de Estudios de Administración Local.

GARCÍA DE ENTERRÍA, E., \& FERNÁNDEZ RODRÍGUEZ, T. R. (2015): Curso de Derecho administrativo I, ed. 17. ${ }^{\mathrm{a}}$, Cizur Menor: Civitas.

GARCÍA LUENGO, J. (2002): La nulidad de pleno derecho de los actos administrativos, Madrid: Civitas.

GARCÍA LUENGO, J., (2016): Las infracciones formales como causa de invalidez del acto administrativo. Un estudio sobre el artículo 48.2 de la ley 39/2015, $1 .^{\text {a }}$ ed., Madrid: lustel.

GARCÍA-TREVIJANO FOS, J. A. (1957): Principios Jurídicos de la organización administrativa, Madrid: Instituto de Estudios Políticos.

GARCÍA-TREVIJANO FOS, J. A. (1986): Los actos administrativos, Fuenlabrada: Civitas. 
DA. Nueva Época - N. 5, enero-diciembre 2018 - ISSN: 1989-8983 - DOI: 10.24965/da.v0i5.10620 - [Págs. 179-185]

Incompetencia manifiesta y usurpación de funciones

Alberto Picón Arranz (España)

GARRIDO FALLA, F. (1956): Régimen de impugnación de los actos administrativos, Madrid: Instituto de Estudios Políticos.

GIANNINI, M. S. (1959): "Atto amministrativo" en Encyclopedia del diritto, IV, Milano: Giuffré.

GONZÁleZZ NAVARRO, F. (1994): Derecho Administrativo Español. Tomo II, Pamplona: Eunsa.

HAURIOU, M. (1943): Précis Elementarie Droit Administratif, 5. ${ }^{a}$ ed., Paris: Recueil Sirey.

SANTAMARÍA PASTOR, J. A. (1972): La nulidad de Pleno Derecho de los Actos Administrativos. Contribución a una teoría de la ineficacia en el derecho público, Madrid: Instituto de Estudios Administrativos.

TRAYTER JIMÉNEZ, J. M. (1994): "Las causas de nulidad de pleno derecho de los actos administrativos" en Administración Pública y Procedimiento Administrativo. Comentarios a la Ley 30/1992, Barcelona: Bosch. 